\title{
The Application of Model-Based Tests for Analysing the Consequences of Methane Combustion in a Mine Heading Ventilated Through a Forcing Air Duct
}

\author{
Jarosław BRODNY*, Magdalena TUTAK**, Antoni JOHN*** \\ *Silesian University of Technology, Faculty of Organization and Management, Roosevelta 26-28, 41-800 Zabrze, Poland, \\ E-mail: jaroslaw.brodny@polsl.pl \\ **Silesian University of Technology, Faculty of Mining and Geology, Poland, E-mail: magdalena.tutak@polsl.pl \\ ***Silesian University of Technology, Faculty of Mechanical Engineering, Konarskiego 18A, Gliwice 44-100, Poland, \\ E-mail: antoni.john@polsl.pl
}

crossref http://dx.doi.org/10.5755/j01.mech.25.3.23739

\section{Introduction}

Methane is responsible for one of the main ventilation hazards in the underground hard coal mining in Poland. Methane hazard is associated with the potential ignition or explosion of this gas in mine headings. Both of these phenomena are extremely unfavourable and can have tragic consequences [1-4]. Methane ignition, which ultimately leads to fires in underground mine headings, disrupts the process of their proper ventilation and exploitation $[1-3,5]$. In this case, the ventilation air stream becomes the source of oxygen, which supports the flame, as well as the carrier of smoke and fire gases, which are moved to further mine headings [1,3]. Therefore, a fire in one mine heading disturbs proper airflow through the others.

In the years 2002-2018, the Polish hard coal mining industry experienced a number of dangerous events related to methane ignition or explosion in mine headings. Those events were most commonly initiated by sparks generated during coal mining with a shearer [6].

Because the methane hazard, which may lead to combustion and explosion of methane when mixed with air, is one of the greatest threats in the mining industry, it is essential to analyse the effects of such events. This is particularly important with regard to the mine ventilation system.

Methane combustion, which leads to exogenous fires in mine headings, triggers a series of chemical reactions that lead to the emission of harmful and poisonous combustion products of high temperature (the temperature of methane combustion in mixture with air is approx. $1,875^{\circ} \mathrm{C}$, with methane content of approx. $10 \%$ ) into the mine atmosphere.

Complete methane combustion occurs according to the following relationship:

$$
\mathrm{CH}_{4}+2 \mathrm{O}_{2} \rightarrow \mathrm{CO}_{2}+2 \mathrm{H}_{2} \mathrm{O}
$$

while incomplete methane combustion is described by the relationships below:

$$
\begin{aligned}
& \mathrm{CH}_{4}+2 \mathrm{O}_{2} \rightarrow \mathrm{CO}+2 \mathrm{H}_{2} \mathrm{O}, \\
& \mathrm{CH}_{4}+\mathrm{H}_{2} \mathrm{O} \rightarrow \mathrm{CO}+3 \mathrm{H}_{2}, \\
& 2 \mathrm{H}_{3}+\mathrm{O}_{2} \rightarrow 2 \mathrm{H}_{2} \mathrm{O},
\end{aligned}
$$

This clearly demonstrates that the process of methane combustion results in the formation of poisonous gasses, such as carbon monoxide and carbon dioxide.

The extremely negative consequences of methane fires in mine headings make it necessary to examine this phenomenon. A huge potential in this regard is offered by model based tests. Such tests are based on measurement data, thus allowing for an analysis of both the possible occurrence of methane fires and their effects. This particularly concerns the impact of fires on the flow parameters of the generated gas mixture.

At the same time, it should be borne in mind that methane combustion is accompanied by dynamic exchange of mass and energy in the reaction zone, whose course is determined by simultaneously occurring chemical, thermal and flow phenomena. A fire is thus an extremely complex phenomenon that eludes clear definition.

Taking into consideration the remarks above, it was assumed that the impact of methane combustion in the mined dog heading on the parameters of the air stream flowing through this heading would be analysed using the CFD model. The analysis encompassed a dog heading where such phenomena are quite common due to its complicated ventilation system.

The purpose of the analysis was to demonstrate the mechanism of occurrence and development of methane fires, as well as to determine their consequences. The model-bases tests of a methane fire were conducted using the "Partially Premixed combustion" (CFD) model.

The objective of the test was to determine the effects of methane combustion on the composition of the mine atmosphere and the physical parameters of the gas mixture generated in this process. The paper presents the distributions for the physical parameters of the resulting gas mixture and the concentration of fire gases. Moreover, it shows the distributions of temperature and oxygen concentration in the headings under analysis.

The article discusses the methodology developed for model-based tests, taking into consideration the actual results of measurements carried out in the heading under analysis. It also presents the results obtained, with particular attention paid to the distributions of combustion products and temperature.

The method developed for analysing methane fires and the results obtained may represent a significant source of information for the mine's ventilation service teams. They should also be used for analysing fire incidents and 
support the process of diagnosing and predicting the effects of these incidents in mine headings.

\section{Mathematical models}

\subsection{Governing equations}

The system of balance equations of mass, momentum and energy (equations of fluid handling) of one-component flow takes the following form [7]:

$$
\frac{\partial \rho}{\partial t}+\frac{\partial(\rho u)}{\partial x}+\frac{\partial(\rho v)}{\partial y}+\frac{\partial(\rho w)}{\partial z}=0
$$

where: $u, v$ and $w$ are directions velocity $(\mathrm{m} / \mathrm{s}), \rho$ is density $\left(\mathrm{kg} / \mathrm{m}^{3}\right)$ and $t$ is time $(\mathrm{s})$.

$$
\frac{\partial}{\partial t}(\rho v)+\nabla \cdot(v v)=-\nabla p+\nabla \tau+\rho g+F
$$

where: $p$ is static pressure $(\mathrm{Pa}), \tau$ is the stress tensor $(\mathrm{Pa}), g$ is the gravitational body force $\left(\mathrm{m} / \mathrm{s}^{2}\right)$ and $F$ is the external body force $(\mathrm{N})$.

$$
\begin{aligned}
& \frac{\partial}{\partial t}(\rho \vec{v})+\operatorname{div}(\rho e \vec{v})= \\
& =\operatorname{div}\left[(-p \stackrel{\leftrightarrow}{I}+\stackrel{\leftrightarrow}{\tau}+\stackrel{\leftrightarrow}{\tau}) \vec{v}+\vec{q}_{s}+\vec{q}_{s}\right]+\rho s_{e} .
\end{aligned}
$$

Ansys Fluent solves the energy equation in the following form [7]:

$$
\begin{aligned}
& \frac{\partial}{\partial t}(\rho E)+\tilde{N}(\vec{v}(\rho E+p))= \\
& =\tilde{N}\left(k_{e f f} \nabla T-\sum_{j} h_{j} \vec{J}_{J}+(\bar{\tau}) \cdot \vec{v}\right)+S_{h},
\end{aligned}
$$

where: $k_{\text {eff }}$ is the effective conductivity, $\vec{J}_{j}$ is the diffusion flux species $j$ and $S_{h}$ includes of heat of chemical reaction.

The basis for a mathematical description of the transportation process of methane released into underground headings is the principle of mass conservation referred to this gas. The mathematical model of transportation, being a set of advection-diffusion equations, which for i-th of this substance $i=1, \ldots . n$, assumes the following form [7]:

$$
\frac{\partial}{\partial t}\left(\rho Y_{i}\right)+\nabla \cdot\left(\rho v Y_{i}\right)=-\nabla \cdot J_{i}+R_{i}+S_{i}
$$

where: $R_{i}$ is the net rate of production of species $i$ by chemical reaction and $\mathrm{Si}$ is the rate of creation by addition from the dispersed phase plus any user-defined sources, $J_{i}$ is the diffusion flux of species and $Y_{i}$ is the local mass fraction of each species.

The flow of air stream through a mining heading is a turbulent flow. This flow features irregular movements of the air stream particles, and the parameters of this flow undergo unpredictable random changes in space and time. A characteristic phenomenon for this type of flow is the occurrence of vortices of different sizes.

In the turbulence model $k-\varepsilon$, in the standard variation, the basic Navier-Stokes equation has been transformed into the Reynolds averaged equation. This equation includes an additional term in the form of the Reynolds stress tensor. Due to this term, the set of equations is not closed. To close the set of equations, it is necessary to introduce additional differential equations, which include the equation of kinetic turbulent energy and the equation of kinetic turbulent energy dissipation in the following form:

$$
\begin{aligned}
& \rho \frac{\partial k}{\partial t}+\frac{\partial}{\partial x_{i}}\left(\rho k u_{i}\right)= \\
& =\frac{\partial}{\partial x_{j}}\left[\left(\mu+\frac{\mu_{t}}{\sigma_{k}}\right)\right] \frac{\partial k}{\partial x_{j}}+G_{k}+G_{b}-\rho \varepsilon-Y_{M}+S_{k}, \\
& \rho \frac{\partial \varepsilon}{\partial t}+\frac{\partial}{\partial x i}\left(\rho \varepsilon u_{i}\right)=\frac{\partial}{\partial x_{j}}\left[\left(\mu+\frac{\mu_{t}}{\sigma_{\varepsilon}}\right) \frac{\partial \varepsilon}{\partial x_{j}}\right]+ \\
& +C_{1 \varepsilon} \frac{\varepsilon}{k}\left(G_{k}+C_{3 \varepsilon} G_{b}\right)-C_{2 \varepsilon \rho} \frac{\varepsilon^{2}}{k}+S_{\varepsilon},
\end{aligned}
$$

where: $C_{1 \varepsilon}, C_{2 \varepsilon}, C_{3 \varepsilon}$ are constans, $\sigma_{k}, \sigma_{\varepsilon}$ are turbulent Prandtl numbers for $k$ and $\varepsilon, G_{b}$ is the generation of turbulence kinetic energy due to buoyancy, $G_{k}$ is the generation of turbulence kinetic energy due to the mean velocity gradients, $Y_{M}$ is contribution of the fluctuating dilatation in compressible turbulence to the overall dissipation rate, $S_{k}, S_{\varepsilon}$ are user-defined source terms.

\subsection{Partially premixed combustion model}

In premixed flames, the fuel and oxidizer are perfectly mixed before they enter the combustor. Reaction then takes place in a combustion zone that separates unburnt reactants and burnt combustion products.

Partially premixed flames exhibit the properties of both premixed and diffusion flames. They occur when an additional oxidizer or fuel stream enters a premixed system, or when a diffusion flame becomes lifted off the burner so that some premixing takes place prior to combustion [8].

The tests were carried out using the partially premixed combustion model and the Zimont's model for calculating the turbulent flame speed.

The partially premixed combustion model is a form of premixed flames model with non-uniform fuel-oxidizer mixtures [7-11].

Turbulent flame combustion model for premixed flame and a PDF for turbulence chemistry coupling who calculates a progress variable $c$ considering the 13 chemical species in chemical equilibrium [12].

The flame front propagation is modelled by solving a transport equation for the scalar quantity $c$, the (Favre averaged) reaction progress variable [7]:

$$
\frac{\partial}{\partial t}(\rho c)+\nabla \cdot(\rho \vec{v} c)=\nabla\left(\frac{\mu_{t}}{S c_{t}} \nabla c\right)+\rho S_{c}
$$


where: $c$ is reaction progress variable, $S_{c t}$ is turbulent Schmidt number for the gradient turbulent flux, $S_{c}$ is reaction progress source term. The progress variable is defined as [7]:

$$
c=\frac{\sum_{i=1}^{n} Y_{i}}{\sum_{i=1}^{n} Y_{i} a d},
$$

where: $n$ is number of products, $Y_{i}$ is mass fraction of species $i, Y_{i}, a d$ is mass fraction of species $i$ after complete adiabatic combustion. Based on this definition, $c=0$ where the mixture is unburnt and $c=1$ where the mixture is burnt. The value of $c$ is defined as a boundary condition at all flow inlets. It is usually specified as either 0 (unburnt) or 1(burnt).

\section{Problem statement and boundary conditions}

The fundamental role for the correctness of the tests is played by the development of a model that will best represent the actual layout of the mine headings and the conditions present in them. In the case at hand, the process of methane combustion was analysed using a 2D model. Despite the fact that, in practice, this process takes place in a spatial system, the authors believe that a 2D flat model acceptably reflects the essence of this phenomenon. It also allows for analysing the mechanism of fire formation and its consequences. The transition from a $3 \mathrm{D}$ to a $2 \mathrm{D}$ model is demonstrated in Fig. 1, whereas the model under analysis is presented in Fig. 2.

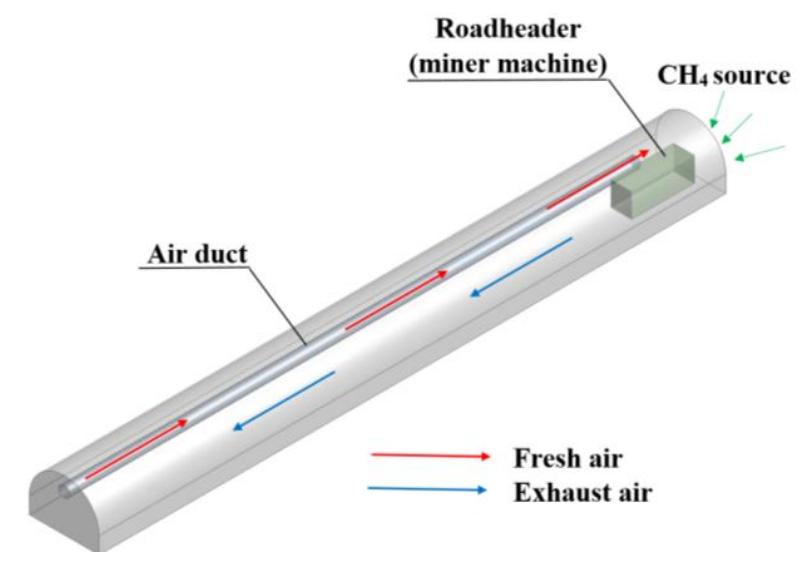

Fig. 1 A 3D geometric model

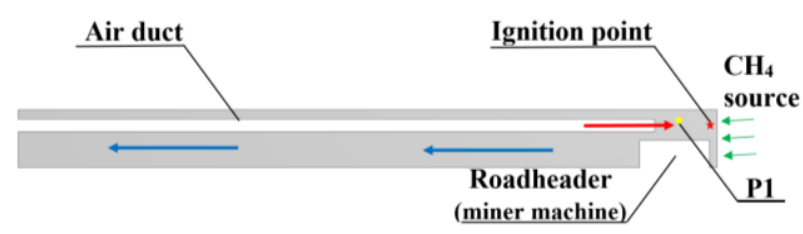

Fig. 2 A 2D geometric model

The section of the mined dog heading, which was the subject of the tests, was 45.0 metres long, and the outlet of air from the air duct was located at a distance of 4 metres from the front side of the mined heading face.

While modelling an exogenous fire of methane, it was assumed to ignite at a distance of $0.5 \mathrm{~m}$ from the frontof the mined heading face, at a height of $2.5 \mathrm{~m}$ (the ignition point is indicated in Fig. 2). This ignition is caused by the sparks generated by the shearer system.

During combustion, methane releases a mass stream of gases into the surrounding environment, including the products of the combustion process. Based on the actual system, the assumption was that air would be supplied to the mined heading face through the air duct with a diameter of 0.8 metre, at a speed of $5.0 \mathrm{~m} / \mathrm{s}$, with the oxygen content in this air being $21 \%$ (mass content -0.23 ). The gases emitted into the atmosphere as a result of methane combustion include carbon monoxide $(\mathrm{CO})$ and carbon dioxide $\left(\mathrm{CO}_{2}\right)$.

During the tests, records were being taken of the concentration levels of fire gases in the air stream as well as the temperature changes for these gases in the measurements points whose location is marked in Fig. 2.

The calculations were performed for a transient state, for the time of 10 minutes (600 seconds). Another assumption was the variable emissions of methane from the front of the mined heading face (Fig. 2). It was assumed that ignition occurs after 180 seconds of analysis and is initiated by a spark. The time course of methane mass stream emissions from the heading face is presented in Figure 3. It corresponds to the methane concentration changes actually registered in this heading while it was being mined.

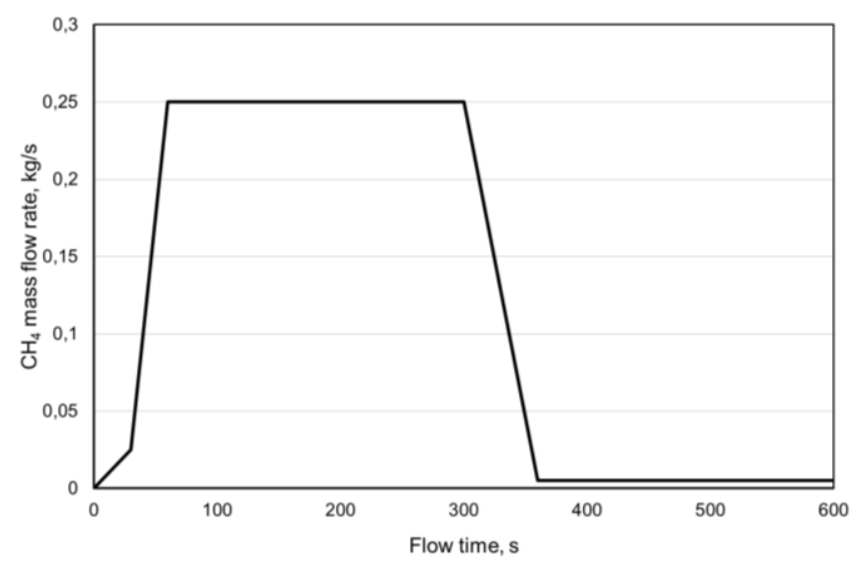

Fig. 3 The time course of methane mass stream emissions from the heading face

\section{Results}

Based on the calculations performed, the changes in the concentration of gases from the air stream flowing through the heading under analysis were characterised as a function of time.

Fig. 4 shows the time-dependent changes in the concentration levels of oxygen, methane, carbon monoxide and carbon dioxide as well as in the temperature in the first measurement point (P1) as a function of analysis time.

Figs. 5 and 6 demonstrate the distributions of fraction the mass $t$ of oxygen and methane in the heading, immediately before the onset of combustion $(t=170 \mathrm{~s})$ and one minutes after this time $(t-240 \mathrm{~s})$, while Figs. $7-10$ present the distributions of carbon monoxide and carbon dioxide as well as temperature for the time point of 1 minutes after the onset of combustion. Fig. 13 also presents the distribution of the progress variable. 


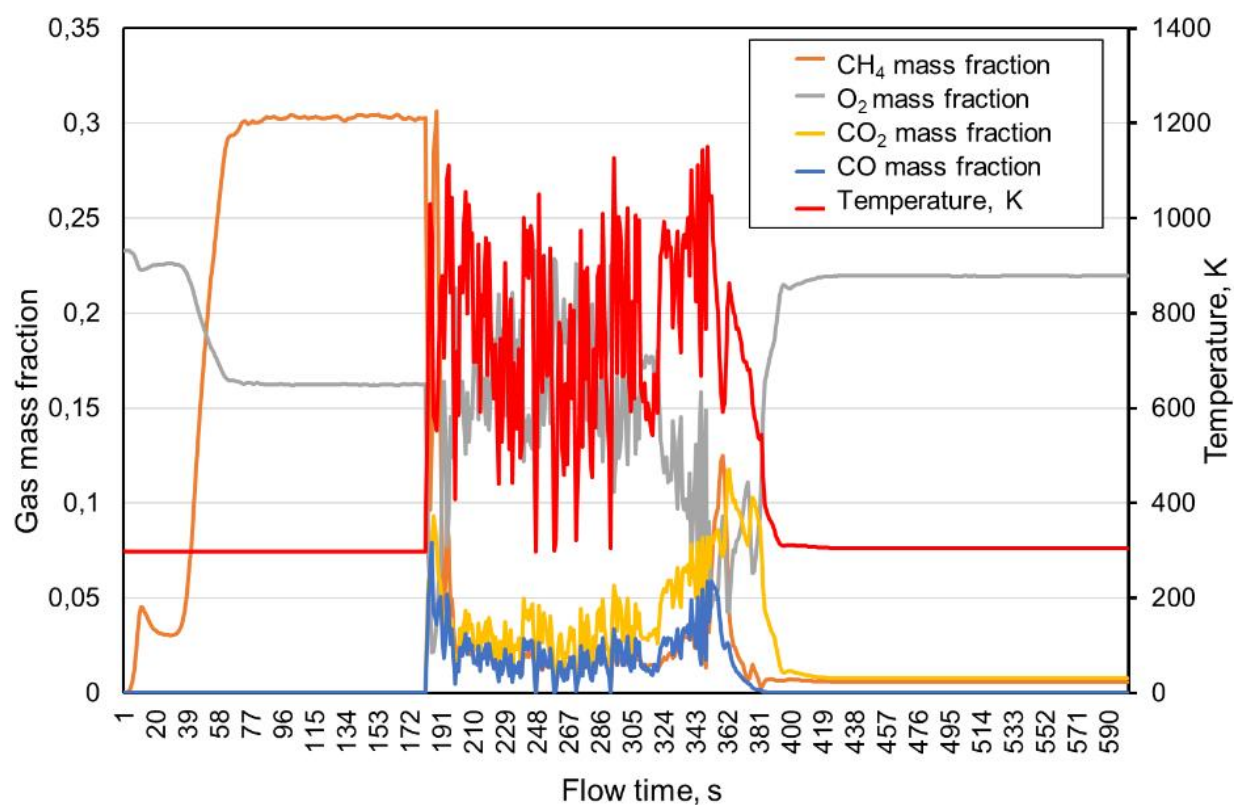

Fig. 4 Time-dependent changes in the concentration levels of oxygen, methane, carbon monoxide and carbon dioxide as well as in the temperature in the first measurement point (P1) as a function of analysis time
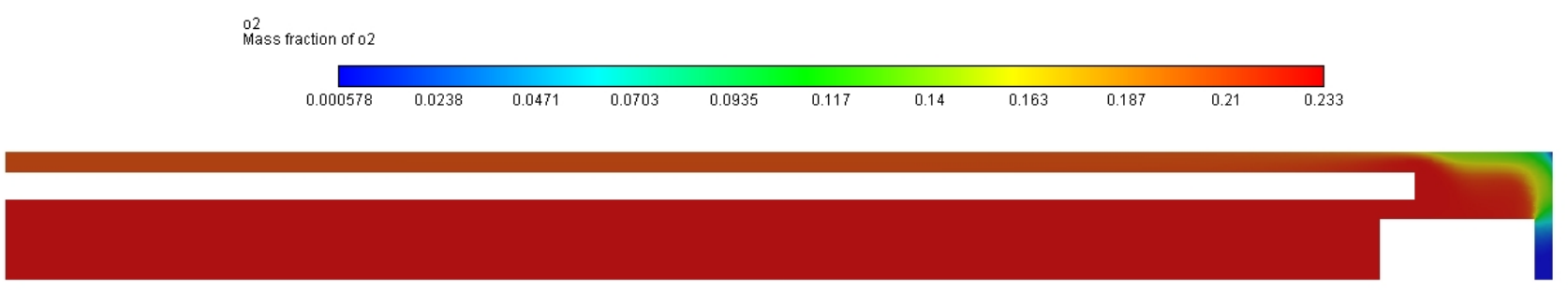

a

Mass fraction of 02

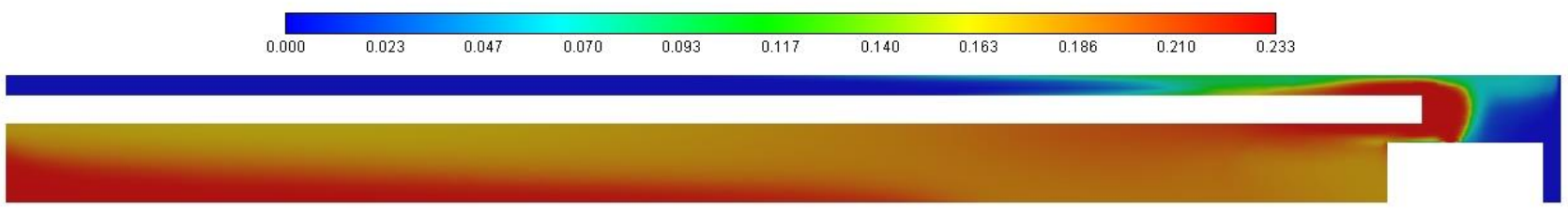

b

Fig. 5 Mass fraction of oxygen in the heading immediately before the onset of combustion (a) and one minutes after this time (b)
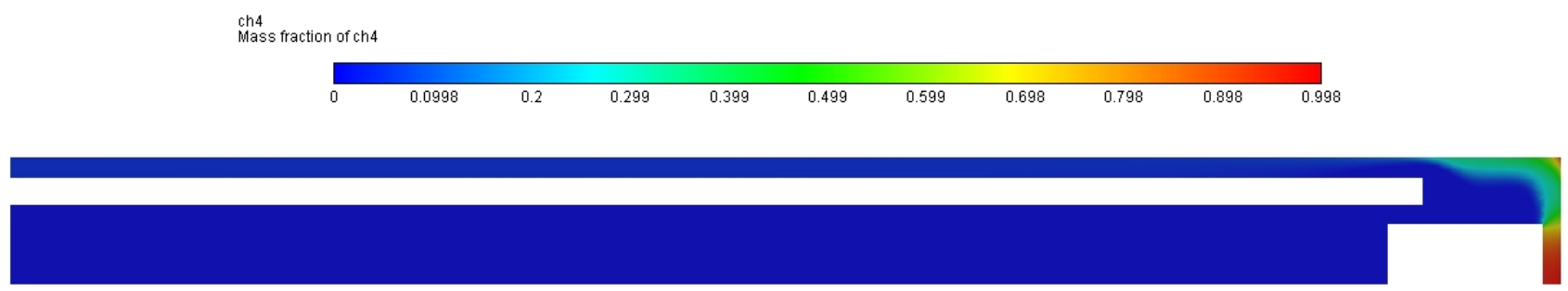

a

ch4
Mass fraction of ch4
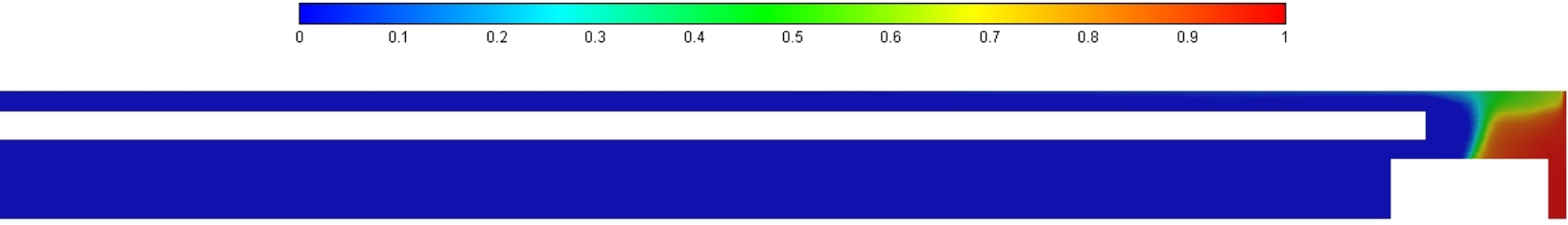

b

Fig. 6 Mass fraction of methane in the heading immediately before the onset of combustion (a) and one minutes after this time (b) 


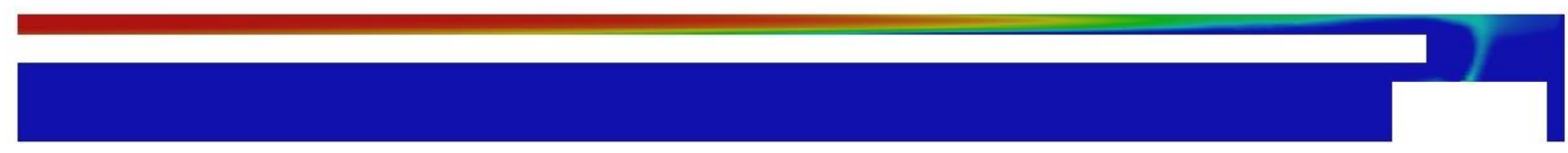

Fig. 7 Mass fraction of carbon monoxide for the calculation time of $t=240$ seconds co2 2 mass fraction of $\mathrm{CO2}$

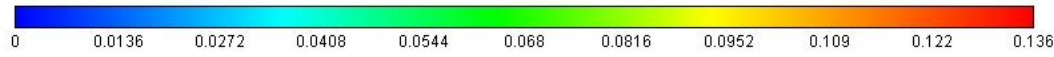

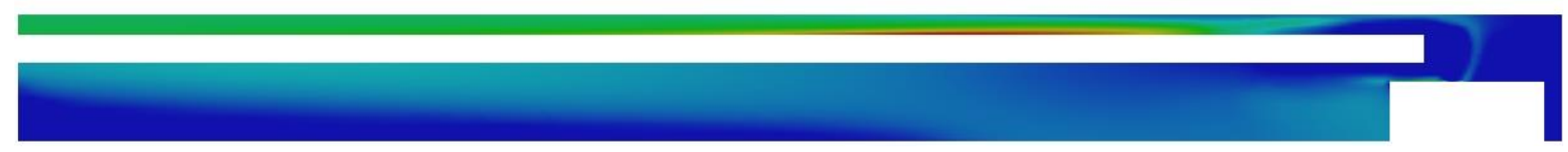

Fig. 8 Mass fraction of carbon dioxide for the calculation time of $t=240$ seconds
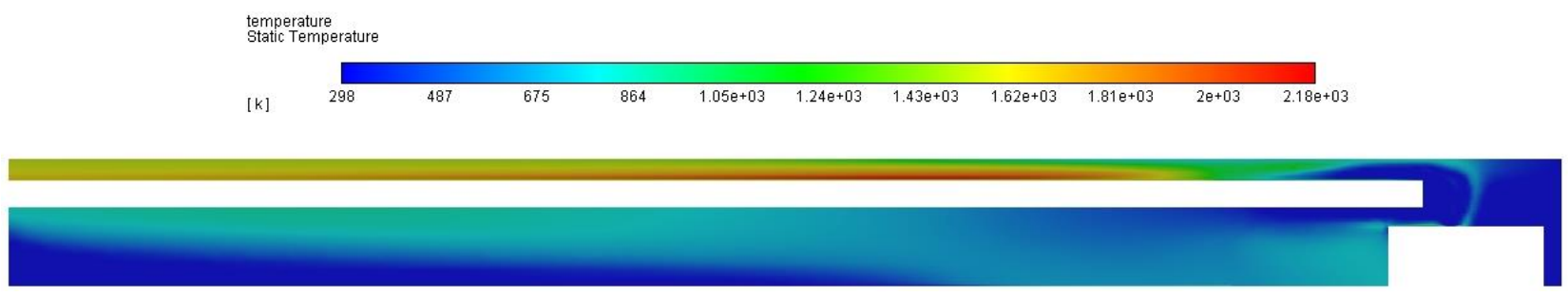

Fig. 9 Distribution of temperature in the heading for the calculation time of $t=240$ seconds

Progress Variable

\begin{tabular}{lllllllllll}
\hline 0 & 0.1 & 0.2 & 0.3 & 0.4 & 0.5 & 0.6 & 0.7 & 0.8 & 0.9 & 1
\end{tabular}

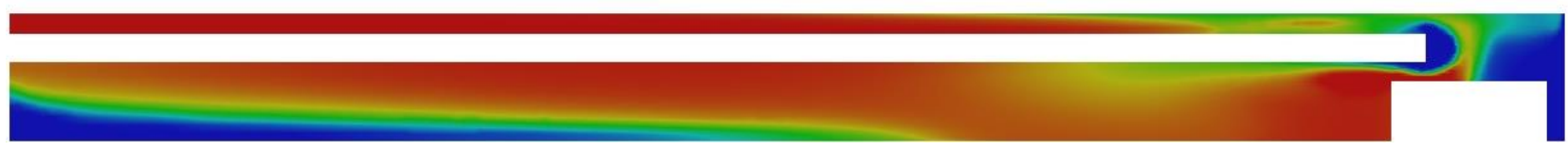

Fig. 10 Distribution of progress variable in premixed combustion for the calculation time of $t=240$ seconds

\section{Conclusions}

Methane fires in mine headings are classified as exogenous fires. Such phenomena are quite common during the process of mining dog headings located in methane seams.

The example presented in the article concerns a real-world mine heading where variable inflow rates of methane were registered. This served as the basis for analysing the occurrence of a methane fire in this heading. The methodology developed and applied for examining the effects of such a fire made it possible to conduct its analysis. The results obtained made it possible to analyse the mechanism behind the formation and development of methane fires, as well as to determine their consequences, especially with regard to the emergence and migration of harmful and poisonous gases with extremely high temperatures. Moreover, the results obtained demonstrate the great dynamics of this process and the considerable danger it may cause.

It is evident that the effects of fire significantly disturb the ventilation process within the heading and may pose a very serious threat to the safety of working crews. The test results should provide an essential source of information for the ventilation service teams in mines. This is because they demonstrate the essence of fire formation and development in a dog heading. Knowledge of this issue should be helpful for developing preventive and protective measures for staff and equipment alike. The analysis conducted also revealed that numerical methods could be successfully used for analysing fire and ventilation phenomena in closed headings. The case at hand may also be treated as a forecast of the consequences brought about by fires. Both the model developed and the methodology adopted are universal enough to be applied to a multivariate analysis of similar phenomena and events.

\section{References}

1. Brodny, J.; Tutak, M. 2016. Analysis of gases emitted into the atmosphere during an endogenous fire, Proceedings of 16th International Multidisciplinary Scientific GeoConference SGEM 2016: 75-82. http://dx.doi.org/10.5593/SGEM2016/HB43/S06.011.

2. Brodny, J.; Tutak, M. 2018. Analysis of methane hazard conditions in mine headings. Analysis of methane hazard conditions in mine headings. Tehnički vjesnik/Technical Gazette 25(1): 271-276. http://dx.doi.org/10.17559/TV-20160322194812.

3. Brodny, J.; Tutak, M. 2018. Determination of the zone with a particularly high risk of endogenous fires in the goaves of a longwall with caving, Journal Applied Fluid Mechanics 11(3): 545-553. 
http://dx.doi.org/10.18869/acadpub.jafm.73.246.27240.

4. Korban, Z. 2015. Quality assessment of occupational health and safety management at the level of business units making up the organizational structure of a coal mine: a case study, International Journal of Occupational Safety and Ergonomics 21(3): 373-381.

5. Wang, Z.; Ren, T.; Ma, L., Zhang, J. 2018. Investigations of ventilation airflow characteristics on a longwall face-A computational approach, Energies 11: 1564.

6. WUG. 2008-2018. www.wug.pl.

7. Ansys Theory Guide, 2011.

8. Karyeyen, S.; Ilbas, M. 2018. Experimental and numerical analysis of turbulent premixed combustion of low calorific value coal gases in a generated premixed burner, Fuel 220: 586-598.

9. Zimont, V. 2000. Gas premixed combustion at highturbulence. turbulent flame closure model combustion model, Experimental Thermal and Fluid Science 21:179-186.

10. Zimont, V.; Polifke, W.; Bettelini, M.; Weisenstein, W. 1998. An efficient computational model for premixed turbulent combustion at high reynolds numbers based on a turbulent flame speed closure, Journal of Gas Turbines Power 120: 526-532.

11. Zimont, V.; Lipatnikov, A. 1995. A numerical model of premixed turbulent combustion of gases, Chem. Phys. Report 14(7): 993-1025.

12. Pope, S. B. 1985. PDF methods for turbulent reactive flows. Progress Energy Combustion Science.
J. Brodny, M. Tutak, A. John

THE APPLICATION OF MODEL-BASED TESTS FOR ANALYSING THE CONSEQUENCES OF METHANE COMBUSTION IN A MINE HEADING VENTILATED THROUGH A FORCING AIR DUCT

\section{S u m m a r y}

One of the most hazardous thermodynamic phenomena occurring in mine headings is fires. One of the substances commonly present in those headings is methane - an easily combustible, odourless gas of natural origin. ethane is released into the mining atmosphere as a result of coal mining activities. Appropriate concentration levels of this gas and the presence of oxygen produce a mixture which can lead to methane combustion and explosion when in contact with an ignition source, such a spark. Both of these phenomena are extremely dangerous, especially in mine headings.

The article presents the results of a numerical analysis concerning methane ignition, leading to an exogenous fire in a mine heading. The purpose of the analysis was to demonstrate the mechanism of occurrence and development of methane fires, as well as to determine their consequences. This is because such fires cause emission of harmful and poisonous gases with extremely high temperatures into the mining atmosphere.

The model-bases tests of a methane fire were conducted using the "Partially Premixed combustion" (CFD) model. The analysis conducted helped to determine the distributions of speed, pressure and temperature of the air stream flowing through the region under analysis, as well as to specify the distributions of concentration levels for the combustion products $\left(\mathrm{CO}\right.$ and $\left.\mathrm{CO}_{2}\right)$.

The article also describes the aerodynamics of the combustion process, as well as the phases of emergence, development and disappearance of fires. The model developed and the boundary conditions adopted for the tests reflect the real-world mine heading. The test method prepared for methane fires and the results obtained may represent a significant source of information for the mine's ventilation service teams.

Keywords: combustion of methane, mine heading, air duct CFD, partially premixed combustion model.

Received March 10, 2019

Accepted June 14, 2019 